\title{
Ultrasonography in acute appendicitis
}

\author{
V Natraj Prasad, Pramod Kumar Chhetri \\ Department of Radiodiagnosis, College of Medical Sciences- Teaching Hospital, Bharatpur, Nepal
}

\section{Correspondence}

Dr. Pramod Kumar Chhetri Department of Radiodiagnosis, College of Medical Sciences-

Teaching Hospital, Bharatpur, Nepal

\section{Email:}

chhetripramod@yahoo.com

DOI: http://dx.doi.org/10.3126/ jcmsn.v13i1.16666

Article received: J an $1^{\text {st }} 2016$ Article accepted: Feb $10^{\text {th }} 2017$

\begin{abstract}
Background \& Objectives: This study was undertaken to establish the Ultrasonographic (USG) findings in acute appendicitis and to establish the accuracy of USG in the diagnosis of acute appendicitis. Materials \& Methods: One hundred patients who presented to the emergency department with a clinical diagnosis of acute appendicitis were subjected to USG. USG findings of those patients suggestive of acute appendicitis were noted. The decision to operate for appendicitis was made on the surgeon's final clinical impression after correlating with USG findings. Histopathological examination of the appendicectomy specimen was taken as the gold standard for the diagnosis of acute appendicitis. Results: USG diagnosis of acute appendicitis is based on a combination of sonographic features. The findings of an aperistaltic tubular structure arising from the caecum with a target appearance on cross section, outer diameter of $>6 \mathrm{~mm}$, mural wall thickness $>3 \mathrm{~mm}$, and probe tenderness over the visualized appendix should prompt the diagnosis in the appropriate clinical settings. The visualization of appendicolith is associated with higher rate of perforation and the visualization of fluid with internal echoes in acute appendicitis could suggest abscess formation. Conclusion: USG is a very useful and essential modality in the diagnosis of acute appendicitis with a sensitivity of $93.93 \%$, specificity of $100 \%$, PPV of $100 \%$, NPV of $89.47 \%$ and an overall accuracy of $96 \%$ in the diagnosis of acute appendicitis.
\end{abstract}

Key words: Acute appendicitis; appendicectomy; ultrasonography

Citation: Prasad VN, Chhetri PK. Ultrasonography in acute appendicitis. JCMS Nepal. 2017;13(1): 203 $-6$.

\section{INTRODUCTION}

In 1554, French physician Jean Fernel first described the term acute typhlitis (derived from the Greek typhlon for caecum) and perityphlitis. Later in 1711, Lorenzo Heister, professor of surgery at Helmstedt, was the first to suggest the appendix as the likely site of primary inflammation. Reginald Fitz, professor of pathology, published a landmark manuscript describing the appendix as the source of inflammation in acute typhilitis. It is Fitz who first coined the term appendicitis. ${ }^{1}$

The vermiform appendix is a blind muscular tube with mucosal, submucosal, muscular and serosal layer. Acute appendicitis is the most common abdominal surgical emergency. ${ }^{2}$ Between five and $10 \%$ of the population develop this condition at sometime in life. The peak incidence is in the second and third decade of life, but can occur at any age. $^{3}$

USG came as a specific tool for preoperative diagnosis of acute appendicitis in 1981 when Deutsch and Leopold reported the visualization of an inflamed appendix for the first time in a young leukemic patient. ${ }^{4}$ Puylaert in 1986 first introduced the graded compression technique for the diagnosis of acute appendicitis. ${ }^{5}$ In this technique, the probe is applied with gradually increasing pressure over the right iliac fossa to displace the bowel loops and visualize the appendix.

\section{MATERIALS AND METHODS}

All patients who presented to the emergency department with a clinical diagnosis of acute appendicitis were subjected to USG. USG examination was done initially using a $3.5 \mathrm{MHz}$ convex probe. Abdominal organs were scanned 
followed by examination of the right iliac fossa using the graded compression technique. The examination was then performed with a $7.5 \mathrm{MHz}$ linear-array transducer. The ascending colon was first identified and traced caudally to locate the caecum. The appendix was then identified as blindending, peristaltic tubular structure arising from the tip of the caecum with a gut signature.

The diagnosis of acute appendicitis was suggested by the presence of an aperistaltic, non-compressible tubular structure in right iliac fossa arising from the caecum with target appearance on transverse section. The maximum outer to outer wall diameter and wall thickness (hypoechoic muscular wall) were measured. Probe tenderness over the enlarged appendix was also noted. USG was considered negative for appendicitis when the appendix could not be visualized or if other pathology was discovered for the cause of pain in the right iliac fossa.

Patients underwent appendicectomy on the basis of the surgeon's final clinical impression after correlating with USG findings. Histopathological examination of the appendectomy specimen was done using routine hematoxylin and eosin staining. The histopathological diagnosis was considered as the gold standard for the diagnosis of acute appendicitis.

\section{RESULTS}

Out of the 100 clinically suspected cases, 74 patients underwent appendicectomy. Histopathological examinations showed acute appendicitis in 44, gangrenous appendicitis in five, gangrenous appendicitis with perforation in 17 and normal appendix in eight. Thus acute appendicitis was confirmed in 66 patients.

Out of the 66 patients with histopathologically proven acute appendicitis, 62 (93.93\%) were diagnosed on preoperative USG. In the remaining 4 $(6.06 \%)$ patients USG failed to visualize the inflamed appendix. Of these four patients, two had perforated appendix, while one was an obese patient and the appendix could not be located, and the other had a malrotated gut with undescended caecum.

USG showed either a normal scan or an alternative diagnosis for the cause of pain in right iliac fossa in 26 of the 100 patients and hence these patients were not operated and were later discharged. Therefore, USG had a sensitivity of $93.93 \%$, specificity of $100 \%$, PPV of $100 \%$, NPV of $89.47 \%$, and an overall accuracy of $96 \%$ in the diagnosis of acute appendicitis.

The USG findings of an aperistaltic, noncompressible tubular appendix with a target sign on cross section and probe tenderness over the inflamed appendix were demonstrated in all the cases with histopathologically confirmed appendicitis thus having $100 \%$ sensitivity and specificity.

The observed maximum outer diameter of the inflamed appendix ranged from 6.1 to $15.8 \mathrm{~mm}$, with an average of $10.0 \mathrm{~mm}$. The observed mural wall thickness of an inflamed appendix ranged from 2.2 to $5.8 \mathrm{~mm}$, with an average of $3.36 \mathrm{~mm}$. However in two cases with histopathologically confirmed appendicitis the wall thickness was less than $3 \mathrm{~mm}$. A grossly distended fluid-filled appendix was seen in these two patients. USG diagnosis of acute appendicitis was however made in these two patients based on the other sonographic findings.

An appendicolith was visualized on USG in nine $(13.63 \%)$ of the 66 patients with appendicitis, which was later confirmed during surgery. Five had perforated appendix and the remaining four had uncomplicated appendicitis. In other words, five (29.41\%) of the 17 patients with perforation had an appendicolith compared to $4(9.09 \%)$ of 44 patients with uncomplicated appendicitis. An appendicolith was thus visualized more frequently in patients with perforation.

Minimal clear fluid collection in right iliac fossa was noted in $10(22.72 \%)$ of the 44 patients with non-perforated appendicitis, while significant collection with internal echoes were noted in all the 17 patients with perforated appendix and pyoperitoneum.

\section{DISCUSSION}

In his original description of the graded compression technique, Puylaert $\mathrm{JB}_{5}$ emphasized that visualization of the appendix alone was the sole criterion for the diagnosis of acute appendicitis by means of USG, as normal appendix was not visualized. Lehmann $\mathrm{D}$ et al. $^{6}$ noted normal appendix in $13(12 \%)$ of their 109 patients, with an average outer diameter of $5.5 \mathrm{~mm}$. Rioux $\mathrm{M}^{7}$ however, reported visualization of normal appendix in $102(82 \%)$ of 125 normal patients. In this present study normal appendix was not visualized.

The average diameter of the inflamed appendix in the present study was $10.0 \mathrm{~mm}$ (range 6.1 to 15.8 
$\mathrm{mm}$ ) and increased diameter as a USG sign of appendicitis was demonstrated in all patients with acute appendicitis (sensitivity and specificity of $100 \%$ ). The present study is in agreement with that of Jeffrey RB et $\mathrm{al}^{8}$ who had concluded that a diagnosis of appendicitis can be made in patients with persistent right iliac fossa pain and an appendicular diameter of $>6 \mathrm{~mm}$. Rettenbacher $\mathrm{T}$ et $\mathrm{al}^{9}$ however, noted appendicular diameter in control subjects (who did not have appendicitis) ranged between two to $13 \mathrm{~mm}$ and in $23 \%$ of these patients the diameter were $>6 \mathrm{~mm}$. Diameter of acutely inflamed appendix ranged from 6 to $30 \mathrm{~mm}$. They concluded that diameter of $>6 \mathrm{~mm}$ can diagnose acute appendicitis with a sensitivity of $100 \%$, but with a poor specificity of $68 \%$, PPV and NPV of $63 \%$ and $100 \%$ respectively, and $79 \%$ accuracy. This diagnostic criterion in their study was more useful in excluding acute appendicitis than in confirming it.

In a study by Jeffery RB et al, ${ }^{10}$ the range of mural thickness of an acutely inflamed appendix varied from three to eight $\mathrm{mm}$, with an average of $3.6 \mathrm{~mm}$. The ranged obtained in the present study was from 2.2 to $5.8 \mathrm{~mm}$, with an average of $3.36 \mathrm{~mm}$. In two cases with confirmed appendicitis the wall thickness measured $2.2 \mathrm{~mm}$. Distended fluid-filled appendixes were seen in these two patients during surgery. Hayden $\mathrm{CK}^{11}$ reported wall thickness in acute appendicitis ranged from two to seven mm, the majority being only two to three $\mathrm{mm}$. Though an exact cut-off value for appendicular wall thickness in acute appendicitis has not been determined, an acutely inflamed appendix, especially when distended by fluid, can have a wall thickness less than $3 \mathrm{~mm} .{ }^{11}$

Probe tenderness over the visualized appendix on USG was very useful in the diagnosis of acute appendicitis and was present in all the patients with acute appendicitis in the present study. Soda K et $\mathrm{al}^{12}$ using this criterion alone achieved a sensitivity of $86.7 \%$, specificity of $89.7 \%$, a PPV of $94.5 \%$, a NPV of $76.5 \%$, and an overall accuracy of $87.6 \%$. This criterion itself was superior to that of the surgeon's initial clinical impression in the author's study.

An appendicolith was visualized on USG in nine $(13.63 \%)$ of the 66 patients with appendicitis in this present study. These patients were diagnosed as having appendicitis by USG based on the increased outer diameter and mural thickness. Appendicolith was just an additional finding. Jeffrey RB et al. ${ }^{8}$ however, noted two patients with surgically confirmed appendicitis having multiple appendicoliths but with an outer appendiceal diameter of less than $6 \mathrm{~mm}$. Thus he concluded that a diagnosis of acute appendicitis can be made even if the maximal outer diameter is $6 \mathrm{~mm}$ or less, when appendicolith is also visualized in patients with right iliac fossa pain. Forel $\mathrm{F}$ et $\mathrm{al}^{13}$ reported three cases with atypical clinical findings and in whom the detection of an appendicolith by USG made the diagnosis of acute appendicitis possible. They were the first to report the sonographic demonstration of an appendicolith in 1983.

In this present study, an appendicolith was seen in 5 (29.41\%) of the 17 patients with perforation, in contrast to four $(9.09 \%)$ of the 44 patients with uncomplicated appendicitis. An appendicolith was thus demonstrated more frequently in patients with complicated appendicitis. Faegenburg $\mathrm{D}^{14}$ studied 17 patients with acute appendicitis and who had appendicolith on abdominal radiography. All had acute appendicitis and 12 were complicated by gangrene or perforation. Thus the demonstration of an appendicolith is not only a strong evidence for acute appendicitis in patients with right iliac fossa pain, even if the outer diameter is less than $6 \mathrm{~mm}$, but also indicates the possibility of perforation.

Though a diagnosis of acute appendicitis was made on USG, gangrenous appendicitis without perforation could not be made on pre-operative USG. Thus, sonographic prediction of a gangrenous appendicitis was poor in the present study. In the 17 patients with gangrenous appendicitis and perforation, the most significant finding to suggest perforation was the demonstration of pericaecal fluid collection containing internal echoes. In a similar study Borushok $\mathrm{KF}$ et $\mathrm{al}^{15}$ noted three sonographic findings that were statistically significant in appendicular perforation: loculated pericaecal fluid, circumferential loss of the echogenic submucosal layer of the appendix, and prominent adjacent pericaecal fat more than $10 \mathrm{~mm}$ thick. The best single sonographic feature in their study was loculated pericaecal fluid indicating an abscess (specificity 100\%). This finding indeed was the only feature to suggest perforation in this present study.

\section{CONCLUSION}

Ultrasonography is a very useful and essential modality in the diagnosis of acute appendicitis with a sensitivity of $93.93 \%$, specificity of $100 \%$, PPV 
of $100 \%$, NPV of $89.47 \%$ and an overall accuracy of $96 \%$ in the diagnosis of acute appendicitis.

Diagnosis is based on a combination of sonographic features. The findings of an aperistaltic tubular structure arising from the caecum with a target appearance on cross section, outer diameter of $>6$ $\mathrm{mm}$, mural wall thickness $>3 \mathrm{~mm}$, and probe tenderness over the visualized appendix should prompt the diagnosis in the appropriate clinical settings. The visualization of appendicolith is associated with higher rate of perforation and the visualization of fluid with internal echoes in acute appendicitis could suggest abscess formation.

\section{REFERENCES}

1. Graffeo CS, Counselman FL. Appendicitis. Gartrointestinal Emergencies Part 11. Emergency Medicine Clinics of North America. 1996 Nov;14:653-71. DOI: 10.1016/S0733 -8627(05)70273-X.

2. Baigrie RJ, Dehn TC, Fowler SM, Dunn DC. Analysis of 8651 appendicectomies in England and Wales during 1992. Br J Surg. 1995;82:933. DOI: 10.1002/bjs.1800820726. PMID: 7648113.

3. Driver CP, Youngson GG. Acute abdominal pain in children: A 25-year comparison. Health Bull. (Edinb.) 1995;53:167.

4. Deutsch MD, Leopard GR. Ultrasonic demonstration of inflamed appendix. A case report. Radiology. 1981;140:163-4. DOI: 10.1148/radiology.140.1.6941334. PMID: 6941334.

5. Puylaert JB. Acute appendicitis: US evaluation using graded compression. Radiology. 1986 Feb.158(2):355-60. DOI: 10.1148/radiology.158.2.2934762. PMID: 2934762.

6. Lehmann D, Uebel P, Weiss H, Fiedler L, Bersch W. Sonographic representation of the normal and acute inflamed appendix - in patients with right-sided abdominal pain. Ultraschall Med. 2000 Jun;21(3):101-6. DOI: 10.1055/s-2000-3788. PMID: 10929595.

7. Rioux M. Sonographic detection of the normal and abnormal appendix. AJR. 1992 April;158 (4):773-8. DOI: 10.2214/ajr.158.4.1546592. PMID: 1546592.

8. Jeffrey RB Jr, Laing FC, Townsend RR. Acute Appendicitis: Sonographic criteria based on 250 cases. Radiology. 1988; 167:327-329. DOI: 10.1148/ radiology.167.2.3282253. PMID: 3282253.

9. Rettenbacher T, Hollerweger A, Macheiner P, Rettenbacher L, Tomaselli F, Schneider B, et al. Outer diameter of the vermiform appendix as a sign of acute appendicitis: evaluation at US. Radiology 2001; 218: 757762. DOI: 10.1148/radiology.218.3.r01 fe20757. PMID: 11230651 .

10. Jeffrey RB Jr, Laing FC, Lewis FR. Acute appendicitis: High-resolution real-time US findings. Radiology. 1987;163:11-14. DOI: 10.1148/radiology.163.1.3547490. PMID: 3547490.

11. Hayden CK. Ultrasonography of the acute pediatric abdomen. Radiologic Clinic of North America. Pediatric Gastrointestinal Radiology.1996 July; 34(4): 791-806.

12. Soda K, Nemoto K, Yoshizawa S, Hibiki T, Shizuya K, Konishi F. Detection of pinpoint tenderness on the appendix under ultrasound is useful to confirm acute appendicitis. Arch Surg. 2001;136:1136-40. DOI: 10.1001/ archsurg.136.10.1136. PMID: 11585505.

13. Forel F, Filiatrault D, Grignon A. Ultrasonic demonstration of appendicolith. J Can Assoc Radiology. 1983; 34:66-7. PMID: 6841426.

14. Faegenburg D: Fecoliths of the appendix: Incidence and significance. AJR 1963; 89:752.

15. Borushok KF, Jeffrey RB Jr, Laing FC, Townsend RR. Sonographic diagnosis of perforation in patients with acute appendicitis. AJR. 1990 Feb; 154:275-8. DOI: 10.2214/ ajr.154.2.2105013. PMID: 2105013. 